\title{
Ações educativas no pré-natal: reflexão sobrea consulta de enfermagem como um espaço para educação em saúde
}

\author{
Educational action in prenatal care: a reflection on nursing \\ consultation as an opportunity for health education
}

Claudia Teresa Frias Rios ${ }^{1}$

Neiva Francenely Cunha Vieira ${ }^{2}$

${ }^{1}$ Universidade Federal do M aranhão. Rua Viana Vaz 230, Centro. 65020-660 São Luís MA.

ctfrios@hotmail.com

2 Universidade Federal do

Ceará.
Abstract In the search for new ways to better reflect on the nursing appointments as an opportunity for prenatal health education, we performed a reflexive study with a qualitative evaluation in which subject participation was a predominant factor. To this end, we used a new paradigm as a methodological reference- the emancipativeevaluation that oriented this research and described reality. Besides non-participative observation, we used the interviews with the five nurses who work at the outpatient ward of the U niversity $\mathrm{H}$ ospital - chosen site for the research - for data collection. In light of the results found, the educational action accomplished by the nurse during prenatal consultation is characterized as a routine action, with little participation, mainly informative, in spite of thegood intention to educate, during which issues regarding the Institution's care, structural and organizational models emerged as obstacles for the accomplishment of education in health as a liberating, transforming and critical-social trend. The research points toward reorienting nursing prenatal care, creating an appropriate physical environment for thenursing consultation and participation of pregnant women in groups. Key words Nursing consultation, Prenatal, Education in health
Resumo $\mathrm{Na}$ busca de novos caminhos que me Ihor refletissem sobre a consulta de enfermagem como um espaço para a educação em saúdeno pré natal, realizamos um estudo reflexivo através de uma avaliação qualitativa, ondea participação dos sujeitos envolvidos foi um fator preponderante. Para tanto, lançamos mão de um novo paradi gma como referencial metodológico, a avaliação emancipatória, quenorteou esta pesquisa etrouxea descrição da realidade. Além da observação não participante, utilizamos para a coleta de dados a entrevista com as cinco enfermeiras que atuam no ambulatório do H ospital Universitário, local escoIhido para a pesquisa. Frente aos resultados encontrados, a ação educativa realizada pela enfermeira durante a consulta do pré-natal caracteriza-se como uma ação rotineira, pouco participativa, com predominância informativa apesar da existência do bom propósito de educar, onde questões relacionadas ao model o assistencial, estrutural e organizacional da Instituição emergiram como obstáculos para a realização da educação em saúde, como ten dência libertadora, crítico-social e transformadora. A pesquisa aponta para a reorientação do serviço de enfermagem na atenção à gestante; a criação de um ambiente físico adequado para 0 atendimento da consulta de enfermagem e a participação da gestante em grupos.

Palavras-chave Consulta de enfermagem, Prénatal, Educação em saúde 
Introdução

O Programa de Atenção Integral à Saúde da M uIher (PAISM) lançado no início dos anos 80 deu ênfase aos cuidados básicos de saú de e destacou a importância das ações educativas no atendimento à mulher, trazendo assim, a marca diferencial em relação a outros programas.

Segundo Penna et al. ${ }^{1}$, a dimensão educativa é, sem dúvida, um dos aspectos mais inovadores do PAISM , pois objetiva contribuir com o acréscimo de informações que as mulheres possuem sobre seu corpo e valorizar suas experiências de vida.

Desse modo, como um dos componentes das ações bási cas de saúde, a ação educativa deve ser desenvolvida por todos os profissionais que integram a equipe da unidade de saúde, estar inserida em todas as atividades e deve o correr em todo e qualquer contato entre profissional de saúde e a clientela, com o objetivo de levar a população a refletir sobre a saúde, adotar práticas para sua melhoria ou manutenção e realizar mudanças, novos hábitos para a solução de seus problemas².

Portanto, o profissional deve ser um instrumento para que a cliente adquira autonomia no agir, aumentando a capacidade de enfrentar situações de estresse, de crise e deci da sobre a vida e a saúde. $E$ um dos momentos na vida dessa mulher, em que ela vivencia uma gama de sentimentos, édurantea gravidez que, sedesejada, traz al egria, se não esperada pode gerar surpresa, tristeza e, até mesmo, negação. Ansiedade e dúvidas com relação às modificações pelas quais vai passar, sobre como está se desenvolvendo a criança, medo do parto, de não poder amamentar, entre outros, são também sentimentos comuns presentes na gestante.

A realização de ações educativas no decorrer de todas as etapas do ciclo grávido-puerperal é muito importante, mas é no prénatal que a muIher deverá ser melhor orientada para que possa viver o parto de forma positiva, ter menos riscos de complicações no puerpério e mais sucesso na amamentação. Considerando o pré-natal e nascimento como momentos únicos para cada muIher euma experiência especial no universo feminino, os profissionais de saúde devem assumir a postura de educadores que compartilham saberes, buscando devolver à mulher sua autoconfiança para viver a gestação, o parto e o puerpério.

0 período pré-natal éuma época de preparação física e psicológica para o parto e para a maternidade e, como tal, é um momento de intenso aprendizado e uma oportunidade para os profis- sionais da equipe de saúde desenvolverem a educação como dimensão do processo de cuidar.

Vários trabalhos sobre a importância do prénatal ou, especificamente, sobre as ações educativas no pré-natal, mostram em seus resultados que, mesmo tendo realizado as consultas, as gestantes demonstram insatisfação com relação às orientações sobre parto, puerpério e cuidados com os recém-nascidos ${ }^{3,4}$.

A parentemente, está havendo uma falha nas ações educativas durante o pré-natal, pois parece paradoxal que a mulher, ao passar por uma gestação sem complicação e freqüentan do o pré-natal, chegue ao último mês demonstrando falta de conhecimento sobre alterações advindas da gravidez e despreparo para vivenciar o parto.

Estes resultados reforçam a nossa preocupação no que diz respeito à forma com que as ações educativas na consulta do pré-natal estão sendo realizadas. Porém, esta pesquisa está direcionada à consulta do pré-natal desenvolvida pelas enfermeiras que atuam na Instituição escolhida para a realização deste estudo, ou seja, um Hospital Universitário (HU).

Diante do exposto, este estudo tem como objetivo descrever as condições de trabalho das enfermeiras na consulta de enfermagem no pré-natal e avaliar sua implicação para a educação em saúde, ratificando a importância das ações educativas para satisfazer as necessidades da gestante que procura o serviço.

\section{Referencial teórico}

Em decorrência ao processo de mobilização social, feministas e profissionais da saúde iniciaram, em parceria com o M inistério da Saúde, a elaboração de propostas de atendimento à mulher que garantissem o respeito a seus direitos de cidadania, o que resultou na estruturação das bases fundamentais do Programa de Assistência I ntegral à Saúde da Mulher.

Assim, o PAISM surge, então, no cenário das Políticas de Saúde nesse período de transição democrática do País, no ano 1984, apontando como metas a ampliação dos problemas a serem tratados pelo setor, a recuperação da função educativa dos serviços e a adoção de uma nova perspectiva de atenção a cada mulher, situando-a em seu contexto social.

Do ponto de vista operacional, o que se pre coniza é a oferta de ações edu cativas que capacitem à mulher o conhecimento do corpo. Tais ações devem, preferencialmente, ser realizadas 
através demetodologias participativas, garantindo assim, que o conhecimento que as mulheres já possuem possa ser intercambiado dentro dos grupos formados nos serviços de saúde. É necessário, portanto, que seja atribuída uma prioridade às ações educativas na assistência à mulher nesta dimensão ${ }^{1}$.

Um fato importante que se ressalta com a implantação do PAISM éo estímulo à participação da(o) enfermeira(o) nas ações de saúde da mulher, especialmente na assistência pré natal.

Deacordo com a Lei do Exercício Profissional da Enfermagem - Decreto n. 9 94.406/87 e o M inistério da Saúde, o pré-natal de baixo risco pode ser inteiramente acompanhado pela enfermeira.

Como descrito na Lei $n .07 .498$ de 25 de julho de 1986, que dispõe sobre a regulamentação do exercício de Enfermagem, cabeà enfermeira realizar consulta de enfermagem e prescrição da assistência de enfermagem; como integrante da equipe de saúde: prescrever medicamentos, desde que estabelecidos em Programas de Saúde Pública e em rotina aprovada pela instituição de saúde; oferecer assistência de enfermagem à gestante, parturiente e puérpera e realizar atividades de educação em saúde ${ }^{5}$.

Sendo o pré-natal um espaço adequado para que a mulher prepare-se para viver o parto de forma positiva, integradora, enriquecedora e feliz, entendemos que o processo educativo (educação em saúde) é fundamental não só para a aquisição de conhecimentos sobre o processo de gestar e parir, mas também para o seu fortalecimento como ser e cidadã.

A carência de informações, ou informações inadequadas sobre o parto, o medo do desconhecido, bem como os cuidados a serem prestados ao recém-nascido nos primeiros dias são fatores mais comuns de tensão da gestante, que influenciam negativamentedurantetodo o processo. É decompetência da equipe de saúde acolher a gestanteea família, desde o primeiro contato com a unidade de saúde. 0 termo acolhimento deve ser considerado na abordagem da grávida como o significado que a gestação tem para ela e sua família, uma vez queénessa fase quese inicia o desenvolvimento do vínculo afetivo com o novo ser.

N este sentido, devem ser valorizados as emoções, os sentimentos e as histórias relatadas pela mulher e seu parceiro deforma a individualizar e a contextualizar a assi stência pré-natal. Para tanto, as autoras Zampieri e Bruggemann ${ }^{6}$ e Saito e Gualda ${ }^{7}$ recomendam utilizar estratégias como a escuta aberta, sem julgamento e preconceitos e 0 diálogo franco, permitindo à mulher falar de suas dúvidas e necessidades, possibilitando, assim, 0 estabelecimento efortalecimento do vínculo profissional-cliente.

Para Freire ${ }^{8}$, somente o diálogo gera um pensar crítico queécapaz, também, de gerar o diálogo. Com a visão do processo educativo numa tendência libertadora, a enfermeira estimula o falar fazendo com que a gestante interfira, dialogue e se sinta capaz. A premissa básica daqueles que realizam o processo educativo dentro dessa perspectiva deve ser a de propiciar o fortalecimento pessoal dos seres humanos com quem interagem. 0 importanteéajudar o ser humano a ajudar-se, fazendo-o agente de sua recuperação, com uma postura crítica e reflexiva de seus problemas.

No pré-natal a(o) enfermeira(o) deve ficar atenta(0) para também, interpretar a percepção que a gestante tem com relação a sua experiência da maternidade no contexto mais amplo (ambiente, família, mudanças físicas, psicológicas esociais) por ser essa uma experiência única. A(o) profissional enfermeira(o) não deve impor seus conhecimentos e desconsiderar a realidade do cliente; caso isto aconteça, as orientações dadas poderão não ser adotadas por incompatibilidade com essa realidade. Conhecer as necessidades de aprendizagem das gestantes no período do pré natal é considerar a importância da cliente na determinação de seu autocuidado.

\section{Aspectos metodológicos}

Para analisarmos a consulta de enfermagem no pré natal como um espaço para a educação em saúde com o olhar crítico e reflexivo dos próprios sujeitos, utilizamos o referencial metodológico pautado no novo paradigma de avaliação qualitativa que éa "Avaliação Emancipatória".

Cronbach, citado por Saul ${ }^{9}$, afirma que um programa de avaliação emancipatória é um processo através do qual os partici pantes compreendem a situação, objeto de estudo, mediante a consideração das interpretações e aspirações daqueles que nela atuam, para oferecer a informação de que cada um dos partici pantes necessita a fim de entender, interpretar e intervir de modo mais adequado.

Os procedimentos previstos por esteparadigma, que se localiza dentre aqueles de abordagem qualitativa, caracterizam-se por métodos dialógicos e participantes que são: a descri ção da realidade; a crítica da realidade e a criação coletiva. Porém este artigo refere-se ao registro e análise das fases de descrição da real idadeea crítica 
da real idade a partir dos sujeitos que vivenciam o problema eas implicações para a promoção da saúde das gestantes. Para Saul ${ }^{9}$, esses momentos incluem a verbalização e a problematização de uma dada realidade.

Para este momento da avaliação, na tentativa de compreender o model o assistencial que determina a realização da consulta de enfermagem e, conseqüentemente, as ações educativas desenvolvidas no pré natal durante a consulta realizada pela(o) enfermeira(o) em um HU, foram levantados dados, inicialmente, a partir da observação não participante, onde procuramos reunir evidências que descrevessem a organização interna do serviço ea rotina da consulta de enfermagem, visando aspectos da ação educativa. Esses dados foram registrados eem seguida reorganizados em um ambiente mais restrito com um espaço curto de tempo entre esses dois momentos para queas imagens estivessem vivas na memória.

Ainda para servir de subsídio na col eta de dados desta pesquisa, foram realizadas entrevistas com os sujeitos. Três perguntas básicas nortearam essas entrevistas para situar as ações educativas realizadas pelas enfermeiras no programa de pré natal: como você vêa consulta deenfermagem no pré natal; como são desenvolvidas as ações educativas e quais as dificuldades encontradas para que essas ações aconteçam neste espaço.

\section{Cuidados éticos do estudo}

Respeitando os aspectos legais necessários, o projeto desta pesquisa foi apresentado ao comitê de ética em pesquisa do Hospital Universitario da Universidade Federal do Maranhão ( $\mathrm{HU} /$ UFM A), tendo sido aprovado em reunião do dia 28 de fevereiro de 2002.

Após obter a permissão para adentrar no campo como pesquisadora, achamos importante para o bom andamento da pesquisa solicitar a participação das col egas enfermeiras que realizam a consulta no pré-natal debaixo risco deforma individual e esclarecer sobre a garantia do anonimato com o intuito de salvaguardar os direitos e interesses dos mesmos. Para tanto, durante a apresentação dos resultados, as enfermeiras que participaram deste estudo serão "re-batizadas" com nomes fictícios. Estes nomes terão relação com a enfermagem, com a educação e a gravidez.

\section{Apresentando a trilha metodológica}

Este estudo foi realizado no Hospital Universitário Unidade M aterno-I nfantil (HUUM I), em São Luís do M aranhão, por ser este uma instituição de referência para o Estado. 0 período para a realização da coleta de dados desta pesquisa foi de quatro meses (março a junho de 2002).

Em março/02 demos início à fase da pesquisa de campo. Começamos o contato com as três enfermeiras que trabalham no ambulatório pela manhã e com as outras duas do turno da tarde, esclarecendo sobre a pesquisa e já agendando o retorno para a realização das entrevistas. Este primeiro contato foi facilitado pelo nosso relacionamento anterior à pesquisa com as profissionais, 0 que não diminuiu, porém, a dificuldade de conciliarmos nossos horários para as entrevistas.

Ao retornarmos ao serviço para as entrevistas, iniciamos paralelamente a observação (direta e não participante) da rotina das consultas, a qual se estendeu até o mês de maio, durante as manhãs e tardes das segundas e quartas-feiras apenas no turno matutino.

De acordo com Leopardi ${ }^{10}$, para a análise dos dados, levamos em consideração palavras ou frases utilizadas repetidamente, respostas dadas em função do conhecimento eexperiências pessoais, idéias principais do grupo e concordâncias entre opiniões das participantes e discutimos à luz do referencial teórico.

\section{Resultados e discussões}

Este capítulo traz a descrição e a crítica da realidade a partir dos dados levantados sob a perspectiva da pesquisadora, através da observação e de documentos pesquisados, assim como sob a perspectiva dos sujeitos, nas transcrições das falas captadas por meio das entrevistas.

\section{Descrição e crítica da realidade}

Criado em janeiro de 1991, o Hospital Universitário (HU/UFM A) é uma instituição pública integrante da rede deensino do M inistério da Educação, cuja prática se efetiva pela prestação de serviços assistenciais aos usuários do Sistema Único de Saúde.

Composto de duas Unidades Hospitalares, 0 H ospital Presidente Dutra e M aterno-Infantil, 0 HU/UFM A constitui-se um destacado centro de formação de recursos humanos e de desenvolvimento de tecnologia para a área de saúde. Está 
sob gestão estadual, sendo referência em procedimentos de alta complexidade para todo o Estado do Maranhão. Como hospital-escola, é um espaço de transmissão do saber e de exercício político, uma forma relevante de educação.

A Unidade Materno-Infantil (HUUMI) possui um serviço de ginecologia e obstetrícia considerado, hoje, um Centro de Referência no Estado, desenvolvendo ações relativas à saúde da muIher na gestação, parto, puerpério, na adolescência ou na vida adulta, como os programas de prevenção do câncer de mama e ginecológico, controle das doenças sexualmente transmissíveis e planejamento familiar, programas esses baseados nas determinações do PAISM. Esta Unidade é ganhadora dos títulos de Hospital Amigo da Criança e de Centro de Referência ao Atendimento Humanizado ao Recém-nascido pelo trabal ho de estímulo ao aleitamento materno e assistência prestada ao recém-nascido que são desenvolvidos na instituição.

O HUUM I está cadastrado no Programa de Humanização no Pré-natal e Nascimento (PH PN) eimplantou a partir defevereiro de 2002 o "SISPRENATAL", um software desenvolvido pelo DATASUS que possibilita o cadastramento e acompanhamento das gestantes no PHPN (até janeiro deste ano foram inscritas 791 gestantes).

As mulheres que procuram o serviço para a realização do prénatal dirigem-se inicialmente à recepção que, na mai oria das vezes, se constitui em um local de grande tensão uma vez que as usuárias que chegam ao Hospital a partir das 6 horas da manhã em busca da consulta médica permanecem na fila de marcação sem garantia de que conseguirão uma vaga e os funcionários ficam ansiosos com a responsabilidade deadequar a oferta à demanda.

0 ambulatório de Tocoginecologia dispõe de cinco obstetras pela manhã e quatro no turno da tarde, cada um atendeem média 16 gestantes por dia. Em relação ao número de enfermeiras que atende à gestante no pré natal, esse serviço dispõe de cinco profissionais, sendo que três atendem pela manhã eduas no turno da tarde. A consulta deenfermagem no pré-natal não éuma atividade com o agendamento diário sistemático. $A$ via deacesso das gestantes às enfermeiras acontece por meio de dois mecanismos: alívio da demanda ou "drenagem da clientela" dado a demanda espontânea à consulta médica, ou através do momento da vacinação através do "encaminhamento" pelo médico.

A forma deacesso paraaliviar a demandanão seconstitui estratégia de cobertura populacional, conforme presente nas normas básicas de atendimentos à gestante nas diretrizes de documentos oficiais do M inistério da Saúde, principalmente no que se refere ao atendimento da gestante de baixo risco. Este fato implica na qualidade do atendimento oferecido, que não oportuniza o estabelecimento de vínculos, confiabilidade, sistematização da assistência, que são elementos importantes para a promoção da saúde da gestante, conforme indica a literatura estudada ${ }^{1,11}$. 0 relato a seguir demonstra a ausência de um agendamento sistemático.

As gestantes só vêem fazer sua primeira consulta no pré-natal conosco quando, por causa da demanda, não conseguem consultar com o médico ou quando elesfaltam, ou seja, a consulta médica é o'carro chefe (Ana Nery).

A enfermeira Maria do Bom Parto ressalta ainda que:

A consulta de enfermagem assume algumas vezes um caráter de concessão do médico ou por local de realização de vacinação uma vez que não há agendamento prévio para primeira vez.

Natividade comenta:

Às vezes acontece de ter um número grande de gestantes que ainda não realizaram a primeira consulta com o médico e outro dia em que só tem consultas subseqüentes, isso por não termos nossas consultas agendadas. Assim, há dias em que temos que sair maistarde e outro queficamos bem mais tranqüilas.

O bserva-seque, ao sefazer a descrição de uma realidade que não nos é satisfatória, essa descrição automaticamente é impregnada pela crítica. Conforme Saul ${ }^{9}$, os momentos de uma avaliação emancipatória se imbricam, ou seja, no momento em que lançamos mão de uma avaliação em que a análise crítica ereflexiva fazem parte desua essência, é natural que haja essa interrelação.

O utros estudos realizados também demonstraram a falta de sistematização da consulta de enfermagem no pré-natal e outras formas de inserção da gestante nos cuidados de enfermagem, como por exemplo:

Cruz $^{12}$, pesquisando a assistência prénatal em Fortal eza, observou divergências relacionadas com o aprazamento das consultas. Havia unidades em que a primeira consulta era sempre marcada para a enfermeira e em outras em que as marcações eram feitas no dia, ou seja, as mulheres chegavam e quando não houvesse mais vaga para o médico eram atendidas pela enfermeira. Um número significativo de unidades de saúde onde a consulta de enfermagem não é"operacionalizada sistematicamente" enquanto em outras 
unidades "foram implantadas de forma parcial, apenas com a sistematização da primeira consulta", caracterizando, assim, segundo a própria autora, que "as ações de enfermagem no pré-natal apontam em direção oposta às normas do M inistério da Saúde".

Nasunidades onde a consulta de enfermagem não é previamente agendada, a enfermeira atende as gestantes que estão aguardando a consulta médica, interrompendo seu atendimento assim que o médico chega e retoma após a cliente ser liberada12.

Compreendemos que, estando as gestantes sob esta forma de cuidado de enfermagem durante sua assistência pré-natal, limita-se a capacidade de estabelecer a consulta de enfermagem conforme o preconizado pelo MS, haja vista que as atribuições das enfermei ras deste serviço não estão otimizadas.

Quando a gestante realiza a sua primeira consulta de pré-natal com a enfermeira, esta preenche o cartão da gestante com os dados de identificação, faz o cálculo da data provável do parto e da idade gestacional através da data da última regra da cliente, registra as aferições do peso, altura e pressão arterial, verificados pela auxiliar deenfermagem. Nesses casos em que a enfermeira realiza a primeira consulta da gestante no pré- natal, esta profissional deve solicitar os exames de rotina estabelecidos pelo M inistério da Saúde. Essa solicitação não étão comum na unidade pesquisada já que, como citado anteriormente, a consulta mé dica é o atendimento de eleição da gestante, em sua primeira visita à unidade de saúde.

Com relação ao acesso da gestante através da procura pelo momento da vacinação, através do "encaminhamento" do médico, fica demonstrado que a visão atribuída ao trabalho das enfermeiras neste serviço limita-se a um procedimento técnico. Conforme as falas a seguir:

A gestante se dirige à sala da consulta de enfermagem, "sala 107" conforme orientação médica e diz: "O médico me mandou tomar uma vacina aqui" ou "Eu vim tomar a vacina que o médico mandou eu tomar aqui, mas eu preciso esperar ou eu já posso entrar?".

As mulheres que entram na sala que é destinada à consulta de enfermagem desconhecem esta atividade como direito, as mesmas procedem de consultas médicas somente. Este tipo de conduta torna-se estranho uma vez que a institucionalização da consulta de enfermagem neste serviço data de 1992.

As gestantes só tomam conhecimento da consulta de enfermagem quando vêm tomar a vacina contra o tétano, aí el as entram achando quevão ser logo vacinadas. Eu esclareço a elas que farão a consulta primeiro para depois serem encaminhadas com o 'cartão da gestante' para a sala de vacina. Algumas, após o atendimento, chegam a dizer 'agora eu entendo por que demorou para eu ser atendida' (Ana Nery).

Além de configurar um problema de organização interna do serviço, o desconhecimento da consulta de enfermagem como direito, trata-sede um aspecto histórico de representação social, onde o enfermeiro/enfermeira ainda não é reconhecido pela população como um profissional que tem competência para se responsabilizar em acompanhar a gestante. A visão medicalizada assistencial, na perspectiva da atenção médica exclusiva, reforça um modelo assistencial centrado nas queixas físicas.

Realmente a consulta de enfermagem precisa que seja vista como uma atividade que a gestante deve realizar não só para tomar a vacina contra 0 tétano, mas onde ela possa ser acompanhada durante todo o pré-natal de baixo risco, além de poder expressar suas dúvidas enecessi dades com mais facilidade ( M aria da Concepção).

Esta forma de acesso à consulta de enfermagem também foi evidenciada no trabalho de $\mathrm{Cruz}^{12}$, que ao chamar a atenção à maneira como o médico se referia à enfermeira para "encaminhar" a gestante para a consulta de enfermagem revelou ainda, segundo a autora, "a relação de poder" entre esses profissionais. A autora transcreve a seguinte fala do médico: "A gora a senhora vai ser encaminhada para asmeninas da enfermagem para tomar a vacina e receber orientações".

O utro aspecto que as enfermeiras que atendem no HUUM I chamaram a atenção, quanto à consulta de enfermagem e já fazendo a relação desse "espaço" para a realização das ações educativas durante o pré-natal, foi o excessivo número deimpressos, além do cartão da gestante, queelas têm que preencher, principalmente durante a realização do primeiro atendimento à cliente. São as anotações no livro de registro das gestantes, no prontuário para preencher a ficha obstétrica e a evolução e no boletim de produção individual, o qual é utilizado para o controle da produtividade de cada profissional.

Eu tento passar todas as informações necessárias para a cliente de acordo com o seu trimestre gestacional. Como o tempo é curto para a demanda atendida e há o excesso de burocracia (registro e anotações) não sei se a gestante ficou com dúvidas, o que prejudica o processo ensino-aprendizagem e em geral ela só escuta sem participar ( Natividade). 
0 tempo médio da consulta de enfermagem no pré-natal, no período de observação desta pesquisa, variou entre 15 a 20 minutos nas consultas subseqüentes e 20 a 30 minutos nas consultas de primeira vez. 0 número máximo de atendimento foi em torno de 14 gestantes por turno e a faixa etária das clientes atendidas era de 18 a 24 anos. Estes dados (número de gestantes atendidas, tempo utilizado na consulta e a faixa etária das gestantes) revelam aspectos que devem ser destacados.

Com relação à faixa etária, esses dados são relevantes quando temos um estudo conduzido no Estado do $M$ aranhão ${ }^{13}$, indicando que mães menores de 20 anos de idade representaram $13,3 \%$ do total de gestantes do Estado e 31,8\% encontravam-se na faixa etária de 20 a 24 anos, 0 que corresponde, em média, à mesma faixa etária das mães atendidas no ambulatório do HUU MI. Caberessaltar queneste serviço existeo atendimento para pré natal de alto risco para o qual são encaminhadas as adolescentes grávidas.

As mães mais jovens têm um risco perinatal mais elevado, menor experiência e a gravidez pode representar uma grande pressão psicológi$\mathrm{ca}$, principalmente entre as primigestas, o que exige uma assistência voltada não somente para o aspecto físico mas, também, para o emocional e para a educação em saúde.

Deacordo com o Informe Epidemiológico da Secretaria Municipal de São Luís, a taxa de mortalidadematerna foi de 70,2 por 100 mil nascidos vivos, com um número absoluto de 14 óbitos de mulheres de 10 a 49 anos $^{13}$. Ainda é ressaltado nesta publicação que $90 \%$ das mortes maternas podem ser evitadas se a mulher receber assistência de boa qualidade no pré-natal, no parto e durante as intercorrências obstétricas.

A efetividade do atendimento pode ser medida quando avaliamos o impacto ocasionado no nível de saúde por meio dosindicadores de mortalidade, morbidade, demográficos, socioeconômicos e ambientais, o impacto das ações de saúde nas condições de vida da população.

Vale destacar que a assistência pré-natal não deve focalizar apenas no biológico para ser adequada, sendo imprescindível organizá-la a partir de necessidades e circunstâncias sociais e ambientais da gestante; para isso, necessário se faz que os profissionais de saúdeestejam preparados para ouvir as queixas das gestantes eesclarecerem suas dúvidas para melhor oportunizar a educação em saúde e, conseqüentemente, fazerem da mulher partícipe.

É notório queos médicos não assumem essepa- pel apesar da ação educativa ser importante para a promoção da saúde. Às vezes os médicos nem falam para as gestantes que devem tomar a vacina contra o tétano, para que, e quando tomar, fazendo parecer que isso só cabe à enfermeira (Paula Freire).

Neste sentido, é importante educar a equipe para uma visão integrada do cuidado da mulher numa concepção de saúde que transcenda os determinantes biológicos. Esta postura de trabal ho também chama atenção de Zampieri e Bruggemann ${ }^{6}$ ao referirem quetodos os profissionais que integram a equipe de saúde devem desenvolver entre si um espírito de reflexão, decisão e trabaIho, que redundem em ações educativas, quepromovam saúde para a população.

De acordo com o PAISM/M S2, a assistência pré natal constitui um conjunto de procedimentos clínicos e educativos com o objetivo de promover a saúde eidentificar precocemente problemas que possam resultar em risco para a saúde da gestante e do concepto. Portanto, não cabe apenas a(o) enfermeira(o) desenvolver a ação educativa durante o prénatal, já que esta atividade faz parte da assistência voltada para esse período.

Por outro lado, é importante, também, que o profissional disponha de tempo para que possa organizar melhor a assistência pré natal epôr em prática as ações educativas durante a consulta, nesse período.

Com relação ao tempo, como foi relatado anteriormente, a média de duração da consulta de enfermagem no pré natal, no período de observação desta pesquisa, variou entre 15 a $20 \mathrm{mi}-$ nutos nas consultas subseqüentes e 30 minutos nas consultas de primeira vez. Segundo o parâmetro estipulado pela Organização M undial da Saúde, a média é de 16 consultas (médicas ou de enfermagem) por turno de trabalho com o tempo de 15 minutos por cliente ${ }^{12}$. Portanto, as consultas deenfermagem observadas decorreram em um tempo maior que a média estabelecida; porém, como não há agendamento prévio, não há uma organização no tempo de realização dessas consultas. Ressalta-se que este tempo da consulta variou em função do trimestre gestacional, além do tipo de consulta (primeira ou subsequente) e queno turno vespertino a demanda émenor, tendo sido observado um dia em quesó houve cinco atendimentos.

De acordo com as falas das enfermeiras, em virtude das mesmas não terem a sua consulta agendada, não sabem previamente quantas consultas de primeira vez ou quantas subseqüentes terão que atender, o que, segundo elas, dificulta o andamento das consultas e, conseqüentemente, 
haverá, na maioria das vezes, menos tempo para as ações de educação em saúde para as gestantes que são atendidas pela primeira vez, já que há mais impressos para preencher.

Ás vezes eu começo a fazer as consultas com poucos prontuários sobre a mesa, nesse momento eu consigo ouvir mais as gestantes e posso dar as orientações com calma. Derepente, a auxiliar traz vários outros prontuários e aí automaticamenteeu começo a me preocupar com o tempo da consulta, principalmente se houver muitas gestantes de primeira vez (Paula Freire).

$\mathrm{Na}$ tentativa de superarem suas dificuldades no trabalho, as enfermeiras procuram estabelecer um diálogo com a gestante e criar uma atmosfera deconfiança, chamando-a pelo nome. Evitam usar termos técnicos, preferindo palavras maissimples, investigam se há alguma queixa e o que a cliente sabe sobre a gestação, al eitamento materno e sobre a vacina contra o tétano neonatal.

No decorrer da consulta, além dos questionamentos iniciais, as enfermeiras apresentam para a gestante um impresso contendo várias informações importantes com relação aos cuidados com o corpo, vestuário, higiene, alimentação, sono e repouso, entre outras, lendo para elas e complementando, quando necessário. Em caso de existir muitas gestantes à espera do atendimento e a cliente atendida for alfabetizada, esta é orientada para que faça uma leitura minuciosa em casa, salientando à gestante a importância daqueleconteúdo para o seu bem-estar.

Segundo as enfermeiras, as orientações dadas às gestantes são relacionadas com o trimestre de gestação em que estas se encontram no momento da consulta; porém, as questões relativas ao aleitamento materno eao ganho ou perda de peso sempre são abordadas independente da idade gestacional.

Antes mesmo de o hospital receber o título de Hospital Amigo da Criança eu já me preocupava em orientar as mães sobre os cuidados com as mamas, observando o tipo do mamilo e informar sobre a importância do aleitamento materno, principalmentenos seis primeiros meses. Por isso, mesmo as orientações sendo dadas deacordo com o trimestre da gestação, em todas as consul tas quea gestante retorna eu falo do aleitamento ( $M$ aria da Concepção).

Como 0 aleitamento materno é essencial para o bebê e a mãe deve ser estimulada e preparada para oferecer o seu leite exclusivamente até 0 sexto mês, desde a sua primeira consulta e em todas as consultas subseqüentes eu falo sobreessetema ( $\mathrm{Na}$ tividade).
Aqui as orientações são dadas de acordo com 0 trimestre gestacional eo acompanhamento do peso e da pressão arterial em todas as consultas (M aria do Bom Parto).

A sala da consulta de enfermagem é ocupada por duas enfermeiras que fazem atendimentos simultâneos, o que declina a qualidade da consulta, em face da não privacidade da cliente. M esmo assim, observamos que ao ser conhecida pela gestante esta função e finalidade do espaço da consulta, um clima de confiança e cordialidade é construído como ficou registrado nas consultas subseqüentes, no comentário de uma gestante atendida pela segunda vez por uma das enfermeiras: "Eu trouxe os exames e ultra-som para o médico, ele olhou, mas não me disse nada e me devolveu. Passei aqui pra mostrar para a senhora e a senhora me explicar".

N esta fala, fica claro que a enfermeira possibilitou uma maior identificação profissional-cliente; isto parece ser um referencial para a consulta de enfermagem como percebemos em um outro momento, eo estabelecimento da confiança entre profissional e cliente, como nesse outro exemplo: "Eu vim tentar marcar uma consulta com outro médico, mas só tem ficha para o mesmo doutor de antes, aí eu não quis. Ele não examina, não pergunta nada e não me diz nada. Eu preferi vir com a senhora".

Importante ressaltar que a consulta de enfermagem, sendo realizada em sala comum por duas enfermeiras que atendem no pré-natal, gera algumas dificuldades para o processo de trabalho da enfermeira, tais como: o ruído da comunicação, pelas fal as das enfermeiras simultaneamente; interrupções, ora pela auxiliar que traz os prontuários, ora por gestante querendo ser atendida "só para tomar a vacina", além da entrada de outros profissionais com problemas administrativos para que uma das enfermeiras, que também respondia pela chefia do ambulatório, fosse resolvê-los; ausência de privacidade das gestantes e descontinuidade do ritmo da consulta.

Segundo o M inistério da Saúde ${ }^{11}$, entreas demais condições básicas para a organização da assistência pré-natal faz-se necessário uma área física adequada, onde a privacidade éum fator essencial para a consulta e para o exame clínico ou ginecológico. 0 que evidenciamos neste estudo não corresponde às normatizações oficiais.

N esse contexto, damos ênfaseà comunicação por ser um veículo facilitador para compreender e compartilhar mensagens enviadas e recebidas. E nas circunstâncias em que elas se dão no serviço de enfermagem, evidenciamos barreiras que 
precisam ser superadas. É importantequeas mensagens e o modo como se dá este intercâmbio influenciem no comportamento das pessoas nele envolvidas a curto, médio e longo prazo.

A comunicação em enfermagem constitui-se um instrumento básico para o cuidado de enfermagem. Uma necessidade humana básica, uma competência que a enfermeira deve desenvolver. E é esta competência que usada de modo terapêutico vai permitir à(o) enfermeira(o) atender o paciente em todas as suas dimensões.

Q uando eventualmente acontece de uma das enfermeiras não comparecer ao serviço, há uma tentativa por parte da profissional que está atendendo de desenvolver uma ação educativa coletiva. Mas, em razão das constantes interrupções, essa tentativa é frustrada como percebemos na fala da M aria da Concepção.

0 espaço físico é inadequado para que se desenvolva alguma técnica de ensino. Às vezes quando a colega não está atendendo eu coloco duas ou três gestantes que estão no mesmo trimestre e dou as orientações de uma só vez para aproveitar o tempo, mas por causa das constantes interrupções não dá para elas sesentirem à vontade, além de dificultar a ação.

Em síntese, diante da descrição e crítica da realidade do serviço, inferimos que as condições nas quais as enfermeiras realizam a consulta de enfermagem têm alcance limitado para envidar estratégias educativas em saúde, para o fortalecimento individual e/ou coletivo das gestantes.

\section{Considerações finais}

Este processo de avaliação não se fez sem dificuldade; porém, a despeito e/ou apesar detodos os óbices, essa experiência valeu a pena. Ela nos levou, pesquisadora e enfermeiras participantes como sujeitos da pesquisa, a reflexões no sentido de apontar que a assistência pré natal para a promoção da saúde da gestante não reflete as idéias que foram objetos de avanço na década de 80, como, por exemplo, a gar antia da participação da mulher na conquista da sua cidadania, no que diz respeito à dificuldade de acesso à informação sobre seu corpo, sua gestação e seu parto.

0 que vimos neste estudo foi o incentivo do aumento da cobertura em detrimento da qualidade, o que não responde às diretrizes das questões normativas das ações básicas de promoção da saúde que propõe a simultaneidade dessas ações.

A saúde como direito deve romper com a visão assistencialista, mecanicista do corpo e apontar para o diálogo, socialização de saberes e práticas entre profissionais e clientes, tanto na preven ção quanto na cura. As relações que se estabelecem entreenfermeiras e gestantes nestas condições organizacionais eassistenciais que se apresentam oferecem limitadas possibilidades de se estabelecer uma comunicação efetiva que possa contribuir para o entendimento da mulher sobre sua condição de saúde, potencialidades e capacidades de mudanças pessoal efamiliar. Ainda nessa perspectiva, a contribuição da consulta de enfermagem para a educação em saúde é prejudicada por ser permeada de ruídos, bloqueios edescontinuidadeno processo comunicativo, massignificativa no aspecto da humanização devido à postura pessoal de suas executoras.

Como ficou visível no bojo das falas das participantes, hán necessidade de segerar esforços para a realização da assistência educativa como forma de melhorar o impacto dessa ação na saúde física, mental eemocional da gestanteduranteo pré natal, quer individualmente ou mesmo coletivamente, sendo importante para isso que a consulta de enfermagem deixe de ser apenas um local de real ização da vacina para a gestante ou local para esclarecer algumas informações que o mé dico não fez ou ainda um local para atender a demanda reprimida.

Por fim, este estudo aponta que, apesar das dificuldades encontradas, faz-senecessário a persistência dos profissionais de enfermagem no sentido de que sejam implementadas atividades que visem à melhoria das ações educativas no pré natal e que o enfermeiro tenha seu papel reconhecido nesse contexto. 


\section{Colaboradores}

CTF Rios trabalhou na concepção, na metodologia, na pesquisa, na análise e interpretação dos dados e na redação do artigo e NFC Vieira, na orientação do trabalho, revisão crítica da pesquisa e aprovação da versão a ser publicada.

\section{Referências}

1. Penna LHG, Progianti JM, Correa LM. Enfermagem obstétrica no acompanhamento pré-natal. R. Bras. Enfer 1999; 52( 3):385-391.

2. M inistério da Saúde. Programa de Assistência Integral à Saúde da M ulher: bases de ação programática. Brasília: M inistério da Saúde; 1984.

3. Araújo RT. Importância da educação para a saúde na assistência pré-natal expresso por gestantes de um Centro de Saúde. In: Anais do XVI Encontro de Enfermagem do Nordeste; 1999; Aracajú. p. 5-11.

4. Pereira RLD. Conhecimento de puérperas sobre sinais de trabalho de parto: avaliação das orientações recebidas no pré-natal [monografia de especialização]. São Luís (M A): Universidade Federal do M aranhão; 2002.

5. Santos EF, et al. Legislação em enfermagem: atos normativos do exercício e do ensino de enfermagem. São Paulo: Editora Atheneu; 2000.

6. Zampiere M FM. Humanizar é preciso: escute o som desta melodia. Florianópolis: Cidade Futura; 2001.

7. Saito E, Gualda DMR. O profissional de saúdefrenteà vivência da dor de parto pela mulher. Revista Técnicocientífico de enfermagem 2003; Curitiba, 1(1): 31-36.

8. Freire P. Educação como prática da liberdade. Rio de Janeiro: Paz e Terra; 1987.

9. Saul AM. Avaliação emancipatória: desafio à teoria e à prática de avaliação e reformulação de currículo. $5^{a}$ ed. São Paulo: Cortez; 2000.

10. Leopardi M T. M etodologia da pesquisa na saúde. Santa Maria: Pallotti; 2001.

11. M inistério da Saúde. Assistência pré-natal: manual técnico. Brasília: M inistério da Saúde; 2005.

12. Cruz MEC. Assistência pré-natal em Fortaleza: estudo a partir da ótica da gestante e dos profissionais de saúde [dissertação]. Fortaleza (CE): Universidade Estadual do Ceará; 2000.

13. Informe Epidemiológico. M ortalidade materna: ainda um desafio. São Luís: Secretaria Municipal de Saúde; 2002.

Artigo apresentado em 20/08/2004

Aprovado em 08/11/2004

Versão final apresentada em 08/11/2004 